Tropical Journal of Pharmaceutical Research January 2021; 20 (1): 35-40

ISSN: $1596-5996$ (print); 1596-9827 (electronic)

(C) Pharmacotherapy Group, Faculty of Pharmacy, University of Benin, Benin City, 300001 Nigeria.

\title{
Bone morphogenetic protein 2/7 promotes repair of bone defect via induction of endochondral ossification
}

\author{
Jianjun Wu*, Changkun Zheng, Guiqing Liang \\ Department of Orthopedics, Fuzhou Second Hospital Affiliated to Xiamen University, Fuzhou 350007, PR China \\ *For correspondence: Email: usehk5@163.com
}

Sent for review: 22 September 2020

Revised accepted: 29 December 2020

\begin{abstract}
Purpose: To study the influence of bone morphogenetic protein 2/7 (BMP2/7) on repair of bone defect, and the mechanism involved.

Methods: Bone marrow stromal cells (BMSCs) were randomly assigned to 2 groups: control and transfection groups. The cells were transfected with rBMP2/7 recombinant adenovirus. Cell growth and alkaline phosphatase (ALP) activity were determined in both groups. Rabbit model of femoral bone defect was prepared using standard methods. Male New Zealand white rabbits were randomly assigned to 3 groups, each of which had 10 rabbits: control, gelatin and BMP2/7 groups. Histopathological and $x-$ ray examinations, and three-point bending flexural test were used to compare the potential of gelatin and BMP2/7 to repair bone defects.

Results: Transfection of BMSCs with $r B M P 2 / 7$ recombinant adenovirus significantly enhanced their growth $(p<0.05)$. Alkaline phosphatase $(A L P)$ level was also markedly and time-dependently higher in transfection group than in control group $(p<0.05)$. Rabbits with grade 4 bone healing or above were more in BMP2/7-treated category than in control and gelatin groups. New bone hyperplasia with typical lamellar bone structure, irregular medullary cavity, as well as transition from osteoblast to osteocyte were observed in BMP2/7 group. Moreover, maximum flexural strength and repair were significantly higher in BMP2/7-transfected group than in control.

Conclusion: These findings indicate that BMP2/7 promotes the repair of bone defect via induction of endochondral ossification in rabbits. Thus, this protein may be useful for the repair of bone defects in humans.
\end{abstract}

Keywords: Alkaline phosphatase, Bone lesions, BMP2/7, Endochondral ossification

This is an Open Access article that uses a fund-ing model which does not charge readers or their institutions for access and distributed under the terms of the Creative Commons Attribution License (http://creativecommons.org/licenses/by/4.0) and the Budapest Open Access Initiative (http://www.budapestopenaccessinitiative.org/read), which permit unrestricted use, distribution, and reproduction in any medium, provided the original work is properly credited.

Tropical Journal of Pharmaceutical Research is indexed by Science Citation Index (SciSearch), Scopus, International Pharmaceutical Abstract, Chemical Abstracts, Embase, Index Copernicus, EBSCO, African Index Medicus, JournalSeek, Journal Citation Reports/Science Edition, Directory of Open Access Journals (DOAJ), African Journal Online, Bioline International, Open-J-Gate and Pharmacy Abstracts

\section{INTRODUCTION}

Bone defects are caused by trauma, bone disease or tumor, congenital abnormalities, infection (osteomyelitis) and failed arthroplasty. Bone defect often leads to bone disconnection, delayed union, fracture, as well as local dysfunction. The maintenance of bone length and union remains a major challenge to orthopedic surgeons. This has necessitated the search for novel and effective bone regeneration therapy. Techniques for reconstruction of bone defects include grafting, distraction osteogenesis, biomaterial and prosthetic implants. 
Bone grafting, a commonly used method for repairing bone defects, comprises autogenous bone graft, allogenous bone graft and artificial bone material filling [1]. Often regarded as the gold standard for bone graft, autogenous bone graft has advantage of being osteoconductive, osteo-inductive and osteogenic. However, it is limited by restricted donor sites and possible harvesting morbidity, unpredictable resorption, and small bone volume [2]. Autogenous graft is superior to allograft, since remodeling and bone healing take place more slowly in allografts, relative to autografts.

In recent years, tissue engineering has made it possible to carry out in vitro construction and in vivo recombination. Bone marrow mesenchymal stem cells (BMSCs) have been used as seed cells in the implantation of scaffold materials. However, the process of osteoblast induction is too complex, requiring the induction of appropriate growth factors $[3,4]$.

A member of the transforming growth factor (TGF) $\beta$ superfamily, BMG stimulates BMSCs to differentiate into osteoblasts and chondrocytes. It also induces ectopic bone formation during healing and repair of bone defects [5]. At present, BMP-2 and BMP-7 are most frequently used. The present investigation focused on the influence of BMP2/7 on repair of bone defect, and the mechanism involved.

\section{EXPERIMENTAL}

\section{Materials}

Sodium pentobarbital injection was bought from Shanghai New Asia Pharmaceutical Co. Ltd. Epinephrine hydrochloride was a product of Tianjin King York Amino Acid Co. Ltd. Penicillin $G$ sodium was obtained from Shanghai Baoman Biotechnology Co. Ltd. Atropine sulfate was purchased from Tianjin Pharmaceutical Group Xinzheng Co. Ltd. Collagen sponge was bought from Hangzhou Lianke Biotechnology Co. Ltd. Pure titanium implant was a product of Zhejiang Guangci Medical Device Factory, while purified recombinant human BMP2/7 was obtained from $R$ \& D Corporation (USA).

Double-digital display constant temperature water bath was bought from Shanghai Chenlian Biotechnology Development Co. Ltd. Vacuum freeze dryer was purchased from Shanghai Jingxin Industrial Development Co. Ltd. Precision electronic universal material testing machine (AGS-H) was bought from Shimadzu Corporation (Japan). Scanning electron microscope was a product of Shanghai Jingke Chemical
Technology Company, while x-ray machine was purchased from Beijing Huarisen Technology Development Co. Ltd.

\section{Cell preparation and culture}

Bone marrow extracted from New Zealand white male rabbits was dispersed into individual cells by subjecting it to density gradient centrifugation at $1500 \mathrm{rpm}$ for $15 \mathrm{~min}$ at $4{ }^{\circ} \mathrm{C}$ using lymphocyte separation solution (a mixture of Ficoll and sodium diatrizoate) as the density gradient solution. The bone marrow stromal cells (BMSCs) were subsequently re-suspended in M199 medium containing $10 \mathrm{ng} / \mathrm{mL}$ vascular endothelial growth factor (VEGF), $10 \%$ FBS, 5 $\mathrm{ng} / \mathrm{mL}$ fibroblast growth factor (FGF) and 5 $\mathrm{ng} / \mathrm{mL}$ epidermal growth factor (EGF). The resultant cell suspension was seeded in culture plates pre-coated with human fibronectin, and cultured in a mixture of DMEM and Ham's F-12 medium (DMEM-F12) containing calcium sulfate at $37{ }^{\circ} \mathrm{C}$ for $72 \mathrm{~h}$ in a humidified atmosphere of 5 $\% \mathrm{CO}_{2}$ and $95 \%$ air. The medium was changed every 2 days. The cells were observed under an inverted microscope, and those in logarithmic growth phase were selected and randomly assigned to 2 groups: control and transfection groups. The cells were transfected with rBMP2/7 recombinant adenovirus.

\section{Determination of ALP activity}

After incubation for 9 days, ALP activity of cells on the composite scaffold was determined using enzyme-linked immunosorbent assay (ELISA).

\section{Rabbits}

New Zealand white male rabbits aged 16 to 20 weeks and weighing $1.8-3.3 \mathrm{~kg}$ (mean age $=18$ \pm 2 weeks; mean weight $=2.55 \pm 0.75 \mathrm{~kg}$ ) were obtained from Beijing Vital River Lab. Animal Tech. Co. Ltd. The rabbits were randomly assigned to 3 groups (10 rabbits/group): control, gelatin and BMP2/7 groups. The BMP2/7 (0.05 $\mu \mathrm{g} / \mathrm{L})$ was prepared in $4 \mathrm{mmoles} / \mathrm{L} \mathrm{HCl}$ containing $0.1 \%$ FBS. Collagen sponges were cut into $15 \times 4 \times 2.5 \mathrm{~mm}$ fragments and sterilized. Each gelatin sponge was made to absorb $100 \mu \mathrm{L}$ of BMP2/7 solution via aspiration, and allowed to dry under aseptic conditions.

This research was approved by the Animal Ethical Committee of Fuzhou Second Hospital Affiliated to Xiamen University (approval no. 2019826638), and was performed according to the guidelines of Principles of Laboratory Animal Care [6]. 
Establishment of rabbit model of femoral bone defect

Each rabbit was anesthetized via intravenous injection of $3 \%$ pentobarbital sodium $(25 \mathrm{mg} / \mathrm{kg}$ body weight) at the edge of the ear. After aseptic preparation of the surgical site (left side of the rabbit's femur), the skin and subcutaneous tissue were cut open and an anterolateral longitudinal incision was made to expose the femur. Bone defects of $10 \times 4 \times 3 \mathrm{~mm}$ (groove-shaped) were then made in the middle of the femur. In the control group, the bone defect area was filled with collagen sponge containing BMP. Rabbits in gelatin group were implanted with gelatin sponge of equivalent size, while BMP2/7 group rabbits were implanted with collagen sponge containing BMP2/7. Penicillin (40 U) was administered to each rabbit twice daily for three days.

\section{Assessment of fracture healing}

Computed radiography (CR) image of each rabbit femur was taken on the day of operation and 12 weeks post-operation. The images were analyzed using Image-Pro Plus analysis software (5.0). Healing of bone defect was assessed via X-ray examination, and was graded using standard grading system: $0=$ absence of new bone formation; 1 = formation of new bone $\leq 25$ $\% ; 2$ = formation of new bone $\geq 25 \% ; 3=$ formation of new bone $\geq 30 \% ; 4=$ formation of new bone $\geq 75 \%$; and $5=$ complete replacement of bone defect area by new bone.

\section{Histological examination of bone tissue}

Histological examination of the fractured area was performed using hematoxylin and eosin $(\mathrm{H}$ \& E) staining 12 weeks after operation. Histopathological changes were assessed based on the degree of inflammatory cell infiltration, osteogenesis, damage, underlying bone destruction and articular cartilage damage. The implanted material was taken out together with near bone segment and fixed in $10 \%$ formalin solution. It was subsequently treated with $10 \%$ EDTA (pH = 7.2) for $72 \mathrm{~h}$ to allow for decalcification. ImageJ analysis software was employed to determine the formation of new bone around the affected area.

\section{Three-point bending flexural test}

Precision electronic universal material testing machine (AGS-H) was used to carry out threepoint bending flexural test. The test was performed in triplicate at 10 min intervals, and the maximum bending strength of new bone was compared amongst the groups. The extent of bone repair (B) was calculated as shown in Eq 1.

$(\mathrm{B})=(\mathrm{St} / \mathrm{Sr}) 100$

where St and $\mathrm{Sr}$ are the maximum bending strengths of new bone and reference control, respectively.

\section{Statistics}

Measurement data are presented as mean \pm SD. Student's $t$-test was used for comparing two groups was performed with. Counting data are expressed as $n(\%)$, and $X^{2}$ test was applied for comparing data amongst groups. All statistical analyses were done with SPSS (21.0). Values of $p<0.05$ were taken as indicative of statistically significant differences.

\section{RESULTS}

\section{Cell growth on scaffold material}

Transfection of BMSCs with rBMP2/7 recombinant adenovirus significantly enhanced their growth $(p<0.05$; Figure 1$)$.

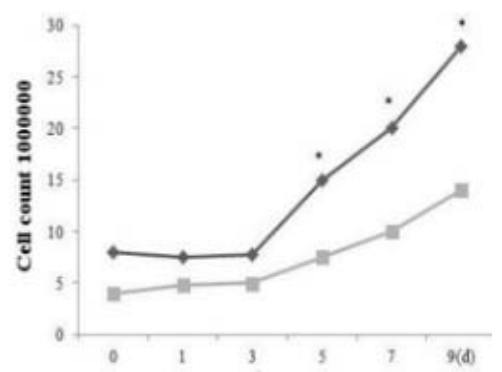

Figure 1: Cell growth on scaffold material. ${ }^{*} p<0.05$, compared with control group. transfected BMP2/7; -untransfected group

\section{Activity of ALP on scaffold material}

As shown in Table 1, ALP activity was significantly and time-dependently higher in transfected cells than in control.

Table 1: ALP activity on scaffold material of each group of cells

\begin{tabular}{lcccc}
\hline Group & Day 3 & Day 7 & $\boldsymbol{t}$ & $\begin{array}{c}\boldsymbol{P} \text { - } \\
\text { value }\end{array}$ \\
\hline Transfection & $0.67 \pm$ & $1.09 \pm$ & 29.699 & $<0.001$ \\
$(\mathrm{U})$ & 0.02 & 0.04 & & \\
Control $(\mathrm{U})$ & $0.33 \pm$ & $0.65 \pm$ & 17.354 & $<0.001$ \\
$T$ & 0.05 & 0.03 & & \\
& 19.966 & 27.828 & & \\
$P$-value & $<$ & $<$ & & \\
\hline
\end{tabular}

Data are presented as mean \pm SD

Trop J Pharm Res, January 2021; 20(1): 37 
Table 2: Grades of healing of bone defect in each group of rabbits

\begin{tabular}{lcccccc}
\hline \multirow{2}{*}{ Group } & \multicolumn{7}{c}{ Grade } \\
\cline { 2 - 7 } & $\mathbf{0}$ & $\mathbf{1}$ & $\mathbf{2}$ & $\mathbf{3}$ & $\mathbf{4}$ & $\mathbf{5}$ \\
\hline Control & $6(60.00)$ & $4(40.00)$ & $0(0.00)$ & $0(0.00)$ & $0(0.00)$ & $0(0.00)$ \\
Gelatin & $10(100.00)$ & $0(0.00)$ & $0(0.00)$ & $0(0.00)$ & $0(0.00)$ & $0(0.00)$ \\
BMP2/7 & $0(0.00)$ & $0(0.00)$ & $1(10.00)$ & $2(20.00)$ & $5(50.00)$ & $2(20.00)$ \\
\hline
\end{tabular}

Results are presented as $\mathrm{n}(\%)$

\section{Healing of bone defect}

At 12 weeks post-operation, CR images of femurs of rabbits in the control group showed that bone callus was formed in a small amount, while the absorption of the broken end appeared thinner. Bone defect area of rabbits in gelatin group revealed non-union image with medullary cavity atresia. However, CR images of femurs of rabbits in BMP2/7 group revealed transformation of callus into woven bone with clear cortical structure (linkage of new bone with broken bone). Moreover, the defect area was full of fibrous connective tissue, inactive bone hyperplasia, and closed medullary cavity. In addition, rabbits with grade 4 bone healing or above were more in BMP2/7-treated rabbits than in gelatin and control rabbits (Table 2 ).

\section{Effect of BMP2/7 on bone histology}

In the control group, new bone hyperplasia, bone trabecula and lamellar bone were observed at the junction of the implant area with host bone. Most of the materials in the center of the implant area were absorbed, and a large amount of fibrous tissue and chondrocytes were also visible. The bone defect area of rabbits in gelatin group was filled with fibrous connective tissue containing inactive bone end hyperplasia, and closed medullary cavity. New bone hyperplasia with typical lamellar bone structure, irregular medullary cavity, as well as transition from osteoblasts to osteocytes were observed in BMP2/7 group. These results are shown in Figure 2.

\section{Three-point bending test data}

As shown in Table 3, maximum flexural strength and percentage repair were markedly higher in BMP2/7 group than in control $(p<0.05)$.

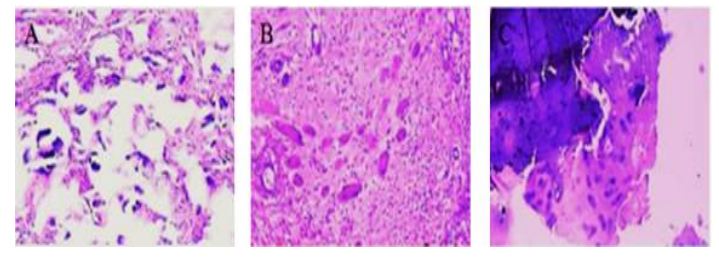

Figure 2: Effect of BMP2/7 on bone histology. A: Control; B: Gelatin; and C: BMP2/7
Table 3: Results of three-point bending test

\begin{tabular}{lcc}
\hline Group & $\begin{array}{c}\text { Maximum } \\
\text { flexural } \\
\text { strength (N) }\end{array}$ & $\begin{array}{c}\text { Bone } \\
\text { repair } \\
\mathbf{( \% )}\end{array}$ \\
\hline $\begin{array}{l}\text { Control } \\
\text { Normal bone control } \\
\text { of the same group }\end{array}$ & $141.64 \pm 15.23$ & 27.02 \\
$\begin{array}{l}\text { BMP2/7 } \\
\text { Normal bone control } \\
\text { of the same group }\end{array}$ & $121.03 \pm 12.72^{*}$ & 86.03 \\
\hline${ }^{*} P<0.05$, compared with control group & \\
\hline
\end{tabular}

\section{DISCUSSION}

The bone plays a vital function in maintaining structural integrity, mineral storage, erythropoiesis, blood clotting and immune response. It is a highly vascularized tissue with inherent healing capacity. Bone defect refers to the absence of bone where it should normally occur. Surgical reconstruction of bone defects can present a significant challenge to orthopedic surgeons. In the treatment of bone defect, autologous/allogeneic bone and other synthetic materials are used to fill the bone gaps and promote fracture healing. However, these strategies generally have limitations such as excessive blood loss in the donor site, small bone volume, as well as complications and aggravation of pain in patients. Advances in bone tissue engineering have made it possible for artificial bone substitutes to be used in clinical practice $[7,8]$.

Seed cells, signal factors and scaffold materials are essential elements needed for tissue engineering.

Bone tissue engineering promotes production of new and viable bone via synergistic interaction amongst biomaterials, cells, and factor therapy. This is viewed as a potential replacement for traditional usage of bone grafts due to its ready availability and zero risk of contracting diseases. At present, autografts are the gold standard for bone grafts due to their being histocompatible and non-immunogenic, while having all characteristics of bone graft substance. Scaffold-based gene therapy is a tissue engineering technique used for transfection of cells to facilitate production of target proteins, or 
for silencing of genes linked to lesions of bone and joint.

Bone morphogenetic protein (BMP) has become the most studied target gene and the most frequently applied in tissue engineering due to its high osteogenic capacity $[9,10]$. It is known that BMP is the only local growth factor that can independently induce bone tissue formation, thereby promoting bone and cartilage repair. Bone morphogenetic proteins (BMPs) 2, 4, 5, 6, 7 and 9 possess high biological properties and strong osteogenic effects. Bone morphogenetic protein (BMP)-2 and 7 are used in spinal fusion and repair of long bone defects [11, 12]. Application of BMP in bone microenvironment at doses higher than physiological dose enhances osteogenesis and osteoclastogenesis [13]. High concentration of BMP2 in cancellous bone promotes osteoclast activity around the implant [14]. Studies have shown that BMP heterodimers possess strong bone-inducing activity. Low-dose concentration of BMP2/7 heterodimer have been demonstrated to effectively improve the function of osteoclasts, and to induce and reshape new bone at an early stage [15]. The high osteoinductive activity of BMP2/7 heterodimer is thought to be due to its increased affinity for BMP receptors [16].

The present study was focused on the influence of BMP2/7 on repair of bone defect, and the mechanism involved. The results showed that BMSCs transfected with rBMP2/7 effectively adhered to scaffold material and grew uniformly. The activity of ALP activity was significantly and time-dependently higher in transfection group than in control group, an indication that transfection of BMSCs with rBMP2/7 may promote osteogenesis in vivo. The results of histological examination showed that at 12 weeks post-operation, femurs of rabbits in BMP2/7 group had new bone hyperplasia with typical lamellar bone structure. Thus, it is likely that BMP2/7 participates in intramembranous osteogenesis (direct conversion of mesenchymal tissue into bone). The results of three-point bending test suggest that the strength of femur after repair of defect reached that of normal bone.

\section{CONCLUSION}

The results of this study indicate that BMP2/7 promotes the repair of bone defect via induction of endochondral ossification in rabbits. Thus, the protein has a potential for use in the repair of bone defects.

\section{DECLARATIONS}

\section{Acknowledgement}

This research was supported by the Natural Science Foundation of Fujian Province (no. 2018J01364).

\section{Conflict of interest}

No conflict of interest is associated with this work.

\section{Authors' contributions}

This study was done by the authors named in this article, and the authors accept all liabilities resulting from claims which relate to this article and its contents. The study was conceived and designed by Jianjun Wu. Jianjun Wu, Changkun Zheng, Guiqing Liang collected and analyzed the data. Jianjun Wu wrote the text. All authors read and approved the manuscript for publication.

\section{Open Access}

This is an Open Access article that uses a funding model which does not charge readers or their institutions for access and distributed under the terms of the Creative Commons Attribution License (http://creativecommons.org/licenses/by/ 4.0) and the Budapest Open Access Initiative (http://www.budapestopenaccessinitiative.org/rea d), which permit unrestricted use, distribution, and reproduction in any medium, provided the original work is properly credited.

\section{REFERENCES}

1. Kawai T, Suzuki O, Matsui K, Tanuma Y, Takahashi T, Kamakura S. Octacalcium phosphate collagen composite facilitates bone regeneration of large mandibular bone defect in humans. J Tissue Eng Regen Med 2017; 11(5): 1641-1647.

2. Wang $X, W u X$, Xing $H$, Zhang G, Shi Q, E L, Liu N, Yang $T$, Wang $D$, Qi $F$, et al. Porous Nanohydroxyapatite/Collagen Scaffolds Loading Insulin PLGA Particles for Restoration of Critical Size Bone Defect. ACS Appl Mater Interfaces 2017; 9(13): 1138011391.

3. Esser JS, Saretzki E, Pankratz F, Engert B, Grundmann $S$, Bode C, Moser M, Zhou Q. Bone morphogenetic protein 4 regulates microRNAs miR-494 and miR-126$5 p$ in control of endothelial cell function in angiogenesis. Thromb Haemost 2017; 117(4): 734-749.

4. Waqas $M$, Sun S, Xuan $C$, Fang Q, Zhang X, Islam IU, Qi $J$, Zhang S, Gao X, Tang M, et al. Bone morphogenetic protein 4 promotes the survival and preserves the

Trop J Pharm Res, January 2021; 20(1): 39 
structure of flow-sorted Bhlhb5+ cochlear spiral ganglion neurons in vitro. Rep 2017; 7(1): 3506-3512.

5. Karyagina AS, Boksha IS, Grunina TM, Demidenko AV, Poponova MS, Sergienko OV, Lyashchuk AM, Galushkina ZM, Soboleva LA, Osidak EO, et al. Two variants of recombinant human bone morphogenetic protein-2 (rhBMP-2) with additional protein domains: Synthesis in an Escherichia coli heterologous expression system. Biochem 2017; 82(5): 613-617.

6. World Health Organization. Principles of laboratory animal care. WHO Chron 1985; 39: 51-56.

7. Maiti SK, Shivakumar MU, Mohan D, Kumar N, Singh KP. Mesenchymal Stem Cells of Different Origin-Seeded Bioceramic Construct in Regeneration of Bone Defect in Rabbit. Tissue Eng Regen Med 2018; 15(4): 1-16.

8. Bolander J, Ji W, Leijten J, Teixeira LM, Bloemen V, Lambrechts $D$, Chaklader M, Luyten FP. Healing of a Large Long-Bone Defect through Serum-Free In Vitro Priming of Human Periosteum-Derived Cells. Stem Cell Reports 2017; 8(3): 758-772.

9. Kim SE, Shim KM, Jang K, Shim JH, Kang SS. ThreeDimensional Printing-based Reconstruction of a Maxillary Bone Defect in a Dog Following Tumor Removal. In vivo 2018; 32(1): 63-70.

10. Mukhopadhaya J, Raj M. Distraction osteogenesis using combined locking plate and llizarov fixator in the treatment of bone defect: $A$ report of 2 cases. Indian J Orthop 2017; 51(2): 222-228.

11. Blanco R, Colombo A, Pardo R, Suazo J. Haplotypebased gene-gene interaction of bone morphogenetic protein 4 and interferon regulatory factor 6 in the etiology of non-syndromic cleft lip with or without cleft palate in a Chilean population. Eur J Oral Sci 2017; 125(2): 102-109.

12. Akatsu $Y$, Yoshimatsu $Y$, Tomizawa T, Takahashi K, Katsura A, Miyazono K, Watabe T. Dual targeting of vascular endothelial growth factor and bone morphogenetic protein-9/10 impairs tumor growth through inhibition of angiogenesis. Cancer Sci 2017; 108(1): 151-155.

13. Ahmad HI, Ahmad MJ, Adeel MM, Asif AR, Du X. Positive selection drives the evolution of endocrine regulatory bone morphogenetic protein system in mammals. Oncotarget 2018; 9(26): 18435-18445.

14. Bao L, LV L, Feng J, Chen Y, Wang X, Han S, Zhao H. MiR-876-5p suppresses epithelial-mesenchymal transition of lung cancer by directly down-regulating bone morphogenetic protein 4. J Biosci 2017; 42(4): 1 11.

15. Parker RM, Malham GM. Comparison of a calcium phosphate bone substitute with recombinant human bone morphogenetic protein-2: a prospective study of fusion rates, clinical outcomes and complications with 24-month follow-up. Eur Spine J 2017; 26(3): 754-763.

16. Song $R$, Wang $D$, Zeng $R$, Wang J. Synergistic effects of fibroblast growth factor-2 and bone morphogenetic protein-2 on bone induction. Mol Med Rep 2017; 16(4): 4483-4492. 